\title{
Social problems of women leprosy patients- a study conducted at 2 urban leprosy centres in Delhi
}

\author{
HARVINDER KAUR* \& V. RAMESH† \\ *National Institute of Immunology, Aruna Asaf Ali Marg, New \\ Delhi 110 067, India; $\dagger$ Department of Dermatology and Leprology, \\ Safdarjung Hospital, New Delhi 110 029, India
}

Accepted for publication 29 April 1994

\begin{abstract}
Summary Leprosy seems to afflict women less commonly than men, but for cultural reasons this difference may be more apparent than real. Unfortunately, the effects are as equally devastating, if not more so, in women than in men. This study, carried out at the Urban Leprosy Centres of Safdarjung Hospital and Dr Ram Manohar Lohia Hospital in Delhi, showed that the impact of stigmata attached to leprosy had more effect on educated women belonging to a higher socioeconomic group than on less fortunate women. Discriminative attitudes were more common in joint than nuclear families. Although many got support from their families, the disease had definite psychological effects. Because of the fear of infecting the family members, women sufferers kept themselves aloof and were constantly worried about divorce. Fear of social ostracism prevented the disclosure of disease to the community. Deformities and disabilities led to a deterioration in their functional capabilities and their psychological state of mind. Pregnancy did not affect regularity of treatment. Many women needed an escort to attend the clinic. Solutions to minimize some problems have been suggested.
\end{abstract}

\section{Introduction}

Leprosy is a major endemic disease in India. It has the second highest prevalence rate of $3 / 1000$ after Myanmar, where it is $15 / 1000{ }^{1}$ Of the $10-15$ million estimated leprosy patients in the world, India has the most, with 4 million. ${ }^{2}$ Every year 470,000 new cases are detected in India alone. ${ }^{3}$ But it should be emphasized that the magnitude of the problem is insufficiently reflected by mere statistics. Sensory-motor deficits in leprosy resulting from peripheral nerve damage manifest as anaesthesia, paralysis and the loss of the function of the hands, feet and eyes. Deformities are the main stigmata, leading to social, psychological and economic problems for patients and their families.

Although morbidity due to leprosy does not differ in men and women, it is the latter who form the most socially vulnerable group. Marriage is difficult and acceptance is not total. ${ }^{4}$ The average rate of divorce that was mainly due to leprosy was $14 \cdot 4 \%$ in Saudi 
women. ${ }^{5}$ Under present Indian law leprosy is still grounds for divorce. The Muslim Marriage Act 1939, Special Marriage Act 1954 and the Hindu Marriage Act 1955 provide clauses for separation and divorce on grounds of a spouse suffering from the disease. ${ }^{6}$ Leprosy has not only physical but also wider social implications associated with cultural, psychological and economic factors. In Turkish women, ${ }^{7}$ besides social, cultural and economic problems, those with leprosy suffered more from stigmata.

In India ${ }^{8}$ women could not work as efficiently as other female members of the family due to disabilities, deformities, or even opposition from family members. As a result, they lost their individuality within the family. Another study ${ }^{9}$ reported that a sizeable proportion experienced problems if they had disabilities of grade II or more. Prejudice emanated mainly from neighbours, relatives and members of the immediate family. ${ }^{10}$

The presence of disabilities and deformities constitutes a major problem in the management of leprosy. However, disabilities were found to be less common in women than men, ${ }^{11-13}$ the male: female ratio being $4: 1 .^{13}$ This has partly been attributed to a lower incidence of lepromatous leprosy in women, ${ }^{14}$ since the disability rate in lepromatous patients is the same in both sexes. ${ }^{15}$

Depression, anxiety and psychosomatic symptoms have been recorded, ${ }^{16}$ and the associated social stigmata act as psychosocial stressors. ${ }^{17}$ A higher suicide rate in leprosy patients as compared with the general population has been reported. ${ }^{18}$ Community surveys in high endemic areas of India have reported higher psychiatric morbidity rates of $99 / 1000^{19}$ and $63 / 1000,{ }^{20}$ arising mainly from physical disability. Specific concerns of leprosy patients include the disease outcome, future security, and loss or change of job. In addition, patients feel guilty, diffident and inadequate.

The present study attempts to identify the nature of the problems faced by women from the northern states of India suffering from leprosy.

\section{Hypotheses}

The following hypotheses have been formulated and tested.

Women with leprosy, irrespective of their socioeconomic status, face social and psychological problems.

Leprosy causes strained relationships between the patient and her husband as well as with other family members.

The nature of the familial structure may influence the incidence of discrimination.

The psychological impact of the disease is directly related to the level of deformity and the visibility of patches.

\section{Subjects}

This cross-sectional study was conducted on 50 women leprosy patients in 2 Urban Leprosy Centres located in New Delhi. Patients who had been treated for a minimum of 6 months, irrespective of the type of disease, whether paucibacillary or multibacillary, were included in the study. They were residents of Delhi, and the adjoining states of 
Uttar Pradesh, Bihar and Rajasthan. There were 2 patients between 0 and 14 years old, 40 patients between 15 and 40 years old and 8 patients were over 40 years old.

\section{Method}

Information was derived from interviews using a schedule designed to test the 4 hypotheses. The validity and reliability of the questionnaire was tested in a pilot study in which 5 patients from each hospital participated. Some amendments were made and the information gathered was also incorporated in the analyses. The final version is given in the Appendix. The interviews were conducted in the clinic by the first author who is a qualified medical social worker. The questions were translated into the local language and explained verbally to all the women leprosy patients included in the study so as to gather appropriate information.

The disability grading recommended by $\mathrm{WHO}^{21}$ was used. Statistical analysis was carried out by the $\chi^{2}$ test using the statistical package TADPOLE III. ${ }^{22}$

\section{Results}

The results are summarized in Tables $1-5$. Table 1 gives details of family income, and the patient's educational, occupational and marital status - 39 were married, 5 were widowed, and 5 were single, including the 2 children.

\section{RELATIONSHIP WITH MEMBERS OF THE FAMILY}

Family means a group of people living together, related to each other through blood or marriage, e.g. including women's husband, children, parents and/or siblings.

As shown in Table 2, 35/39 of the husbands were aware of the disease. Of these 26/35 were cooperative, but relationships were strained with $9 / 35$, irrespective of their educational status. In 41/50 the women's families were aware of the disease. Discrimination was faced by $10 / 41$ patients. Out of 41 cases, 26 women were members of nuclear

Table 1. Profile of patients' education, occupation and marital status with family income

\begin{tabular}{|c|c|c|c|c|c|c|c|c|c|c|}
\hline \multirow{2}{*}{$\begin{array}{l}\text { Family income } \\
\text { (Rupees/month) }\end{array}$} & \multicolumn{4}{|c|}{ Education } & \multicolumn{3}{|c|}{ Occupation } & \multicolumn{3}{|c|}{ Marital status } \\
\hline & I & $\mathrm{P}$ & $\mathrm{S}$ & $\mathrm{G}$ & $\mathrm{Hw}$ & $\mathrm{Se}$ & St & $\mathrm{Si}$ & $\mathrm{Ma}$ & Wi \\
\hline$<1000$ & 9 & 2 & - & - & 8 & 3 & - & - & 10 & 1 \\
\hline $1000-2000$ & 15 & 6 & 2 & - & 19 & 3 & 1 & 3 & 18 & 2 \\
\hline $2000-3000$ & 3 & 4 & - & 1 & 7 & 1 & - & 1 & 6 & 1 \\
\hline$>3000$ & 5 & - & - & 3 & 6 & 1 & 1 & 2 & 5 & 1 \\
\hline Total & 32 & 12 & 2 & 4 & 40 & 8 & 2 & 6 & 39 & 5 \\
\hline
\end{tabular}

I, illiterate; P, primary; S, secondary; G, graduate; Hw, housework; Se, service; St, student; Si, single; Ma, married; Wi, widowed. 
Table 2. Educational level of patients and their family relationships

\begin{tabular}{|c|c|c|c|}
\hline \multirow[b]{2}{*}{ Relationships to the patient } & \multirow[b]{2}{*}{ Awareness of disease } & \multicolumn{2}{|c|}{ Attitude } \\
\hline & & Cooperative & $\begin{array}{c}\text { Discriminative/ } \\
\text { strained }\end{array}$ \\
\hline Spouse & $35 / 39(89 \cdot 74)^{*}$ & $26 / 35(74 \cdot 28)$ & $9 / 35(25 \cdot 71)$ \\
\hline Family members & $41 / 50(82)$ & $31 / 41(75 \cdot 6)$ & $10 / 41(24 \cdot 39)$ \\
\hline \multicolumn{4}{|l|}{ Education levels of patients } \\
\hline Illiterate & $24 / 32(75)$ & $18 / 24(75)$ & $6 / 24(25)$ \\
\hline Primary & $11 / 12(91 \cdot 6)$ & $8 / 11(72 \cdot 7)$ & $3 / 11(27 \cdot 2)$ \\
\hline Secondary & $2 / 2(100)$ & $2 / 2(100)$ & $0 / 2$ \\
\hline Graduate & $4 / 4(100)$ & $3 / 4(75)$ & $1 / 4 \quad(25)$ \\
\hline \multicolumn{4}{|l|}{ Family type } \\
\hline Nuclear family & $26 / 32(81 \cdot 25)$ & $21 / 26(80 \cdot 26)$ & $5 / 26(19 \cdot 23)$ \\
\hline Joint family & $15 / 18(83 \cdot 33)$ & $10 / 15(66 \cdot 66)$ & $5 / 15(33 \cdot 33)$ \\
\hline
\end{tabular}

Difference in discriminative/strained attitude between nuclear and joint families not statistically significant at the $5 \%$ level. This was analysed using the $\chi^{2}$ test.

* Numbers in parentheses are percentages.

families, 5 of them meeting with discrimination. The remaining 15 belonged to joint families, and 5 of these faced discrimination.

RELATIONSHIP WITH THE COMMUNITY

Communities of $16(32 \%)$ patients were aware of their diseased condition, and 5 $(31 \cdot 25 \%)$ of these patients were not allowed to use common community places, $11 / 16$ $(68 \cdot 8 \%)$ were allowed to interact with other members of the community, and $7 / 16$ $(43 \cdot 8 \%)$ faced abuse because of the disease.

\section{PSYCHOLOGICAL IMPACT ON THE PATIENTS}

In all, 25 out of 50 patients were afraid of infecting their families. Of the 50, 33 were illiterate and 17 had been educated (Table 3); 13 out of the 33 illiterates had this fear and $8 / 13$ distanced themselves; 12 of the 17 educated women were af raid of infecting others, but only 6 distanced themselves.

THE PSYCHOLOGICAL STATE OF MIND

In spite of a cooperative attitude from the husband, 10/39 (25.6\%) women were worried about divorce, $31(62 \%)$ women had a tendency to get angry over trivial matters and 35/ $50(70 \%)$ were easily upset since contracting the disease; $15(30 \%)$ of them also preferred to remain alone.

THE PROBLEMS FACED IN TREATMENT COMPLIANCE

Out of the 50 interviewed, $30(63.82 \%)$ had no difficulties in attending the clinic 
Table 3. Correlation between psychological impact of leprosy and educational levels

\begin{tabular}{lcccc}
\hline & $\begin{array}{c}\text { No. of } \\
\text { Edients }\end{array}$ & $\begin{array}{c}\text { Fear of } \\
\text { inf ecting others }\end{array}$ & Yes & No \\
\cline { 3 - 5 } Illiterate & 33 & $13(39 \cdot 39)^{*}$ & $8(24 \cdot 24)$ & 25 \\
Primary and secondary & 13 & $8(61 \cdot 53)$ & $5(38 \cdot 46)$ & 8 \\
Graduate and above & 4 & $4(100)$ & $1(25)$ & 3 \\
Family type & & & $\mathrm{N}-8$ & $\mathrm{~N}-24$ \\
$\quad$ Nuclear (N) & 32 & $\mathrm{~N}-14$ & $\mathrm{~J}-12$ \\
$\quad$ Joint (J) & 18 & $\mathrm{~J}-11$ & 14 & 36 \\
Total & 50 & $25 / 50$ & & \\
\hline
\end{tabular}

Difference between illiterate and educated patients not statistically significant at the $5 \%$ level. This was analysed using $\chi^{2}$-test.

* Numbers in parentheses are percentages.

regularly; 18 faced the problem of travel expenses. A total of $16(32 \%)$ adults needed an escort and 2 were dependent children.

There were $12(24 \%)$ women who were not fully satisfied with the response to treatment due to the persistence of macules, a loss of sensation, reactions and deformities.

Of the 37 married women, $19(51 \cdot 4 \%)$ became pregnant, 16 during the course and 3 before beginning treatment; $5(30 \cdot 8 \%)$ discontinued treatment during pregnancy.

\section{DISABILITY GRADING AND EFFECTS ON EFFICIENCY AT WORK}

There were $31(62 \%)$ with disabilities, which were mild in 19 , moderate in 9 and severe in $3 ; 28$ women were certain that their efficiency would decline.

There were 29 women who felt ashamed or embarrassed by their physical imperfection, and $24(77 \cdot 4 \%)$ feared that people would question them about their deformity and skin patches and identify their disease. In $14(45 \cdot 6 \%)$ routine work was compromised by the disability, and 26 were concerned regarding the curability of the disease.

\section{Discussion}

Nearly all (48/50) women in this study were of reproductive age and married. Economically, they belonged to low and lower middle-income groups, as reported in a WHO study. ${ }^{23}$

Illiteracy and the early drop-out of women at the elementary school level was seen in each socioeconomic stratum, indicating the low priority given to the education of women. There were 6 (out of 23) women in the middle, higher-middle and high-income groups families who attained higher education and therefore better opportunities of having economically sound positions (Table 1 ).

There were 42 (out of 50) women (including 2 students), who, irrespective of their socioeconomic or marital status, were engaged in household work and therefore financially dependent on their husbands and families. 
Table 4. Relationship with other people in the family and community

\begin{tabular}{llccc}
\hline Author & \multicolumn{1}{c}{ Subjects } & $\begin{array}{c}\text { Strained } \\
\text { intrafamilial } \\
\text { relations }\end{array}$ & $\begin{array}{c}\text { Fear of social } \\
\text { ostracism }\end{array}$ & $\begin{array}{c}\text { Social } \\
\text { malad justment }\end{array}$ \\
\hline Sabesan et $^{\text {al. }}{ }^{17}$ (Madurai) & Men & $125 / 200(62 \cdot 5)^{*}$ & - & $114 / 200(57)$ \\
Kant $^{7}$ (Gu jarat) & Men and women & $51 / 210(24 \cdot 2)$ & $72 / 210(34 \cdot 2)$ & - \\
Naik et al ${ }^{8}$ (Bombay) & Women & $11 / 101(11 \cdot 0)$ & - & - \\
Naik et al ${ }^{9}$ (Goa) & Women & $2 / 26(8 \cdot 0)$ & - & - \\
Kaur and Ramesh (present study) & Women & $10 / 41(25 \cdot 0)$ & $34 / 50(68 \cdot 0)$ & $6 / 16(37 \cdot 5)$ \\
\hline
\end{tabular}

* Numbers in parentheses are percentages.

\section{RELATIONSHIP WITH FAMILY MEMBERS}

Although many spouses and other family members were aware of the patients' illness and supported them in getting treatment, 9/35 had marital problems and 10/41 had strained intrafamilial relationships, as observed earlier. ${ }^{8}$

Over half the patients tended to hide the disease, mostly due to fear of ostracism, and had to attend to all matters relating to their treatment by themselves.

Strained intrafamilial relations adversely affected the patients. The effects varied, reflecting the social and cultural background, and literacy in a given locality. Our figures for social ostracism appeared high when compared to other studies, possibly because our study was confined to women while the other studies dealt only with males or both sexes (Table 4).

With better education there was increased awareness amongst the family members about the disease. This was lacking in patients from lower socioeconomic groups who were more concerned about their symptoms than the disease. Their low economic and social conditions did not elicit serious social reactions.

Whilst many families aware of the disease were understanding and supportive towards the patient, a significant number of patients from both illiterate and educated families faced discrimination. Families with more than 1 case of leprosy were more cooperative. In 5 such families studied, the husband who was being treated for leprosy brought his wife to the clinic when she developed it and this cooperation led to a better compliance with treatment.

There was no significant difference between patients coming from nuclear or joint families with regard to level of awareness of the disease. It appeared that there was a higher discriminative attitude to women in joint families. In South India leprosy has resulted in the break-up of joint families. ${ }^{24}$

\section{RELATIONSHIP WITH COMMUNITY}

Because of the fear of social ostracism, almost double the number of the women, as compared to a previous study including both men and women, ${ }^{8}$ hid their disease from society (Table 4$)$.

Despite experiencing discrimination most of the patients mingled freely in the 
Table 5. Psychological and psychosocial problems in leprosy

\begin{tabular}{|c|c|c|c|c|c|c|c|c|}
\hline Author & Subjects & $\begin{array}{c}\text { Worried } \\
\text { about } \\
\text { divorce }\end{array}$ & Aggressive & $\begin{array}{c}\text { Emotionally } \\
\text { unstable/ } \\
\text { solitary } \\
\text { nature }\end{array}$ & $\begin{array}{c}\text { Embarrassment } \\
\text { due to } \\
\text { deformity/ } \\
\text { patches }\end{array}$ & $\begin{array}{l}\text { Other } \\
\text { people's } \\
\text { concern }\end{array}$ & $\begin{array}{l}\text { Decreased } \\
\text { ability }\end{array}$ & $\begin{array}{l}\text { Concerned } \\
\text { regarding } \\
\text { curability }\end{array}$ \\
\hline $\begin{array}{l}\text { Sabesan et al. } \\
\quad \text { (Madurai) }\end{array}$ & Men & ND & $\begin{array}{l}35 / 200 \\
(17 \cdot 5) \dagger\end{array}$ & $\begin{array}{c}117 / 200 \\
(58 \cdot 5)\end{array}$ & ND & ND & ND & ND \\
\hline $\begin{array}{l}\text { Price }{ }^{* 21} \\
\text { (Bombay) }\end{array}$ & Men and women & ND & ND & ND & $\begin{array}{c}11 / 91 \\
(12 \cdot 08)\end{array}$ & $\begin{array}{c}11 / 91 \\
(12 \cdot 08)\end{array}$ & $\begin{array}{c}16 / 91 \\
(18)\end{array}$ & $\begin{array}{l}6 / 91 \\
(7)\end{array}$ \\
\hline $\begin{array}{l}\text { Reddy }^{9} \\
\quad \text { (Pondicherry, S. India) }\end{array}$ & Men and women & ND & ND & ND & ND & $2 \cdot 91 \%$ & $19 \cdot 36 \%$ & ND \\
\hline $\begin{array}{l}\text { Ramanathan et al. }{ }^{12} \\
\text { (Jalma, Agra) }\end{array}$ & Men and women & \multicolumn{7}{|c|}{$55 \%$ had psychiatric morbidity (including depression, anxiety, neurotic/somatic symptoms, etc.) } \\
\hline $\begin{array}{l}\text { Kaur \& Ramesh (present study) } \\
\text { (Delhi) }\end{array}$ & Women & $\begin{array}{c}10 / 39 \\
(25 \cdot 64)\end{array}$ & $\begin{array}{r}31 / 50 \\
(62)\end{array}$ & $\begin{array}{c}15 / 50 \\
(30)\end{array}$ & $\begin{array}{c}29 / 31 \\
(93 \cdot 54)\end{array}$ & $\begin{array}{c}24 / 31 \\
(77 \cdot 41)\end{array}$ & $\begin{array}{c}14 / 31 \\
(45 \cdot 16)\end{array}$ & $\begin{array}{c}26 / 31 \\
(83 \cdot 87)\end{array}$ \\
\hline
\end{tabular}

* Over $64 / 91(70 \%)$ had the combination of these reactions.

$\dagger$ Numbers in parentheses are percentages.

ND, Not done in the study. 
community. This reflects impact of health education through the mass media. However, there still is scope for improvement to root out discrimination.

\section{PSYCHOLOGICAL IMPACT ON WOMEN}

In all, $50 \%$ of our respondents kept themselves aloof for fear of spreading infection. This fear, arising from self-incrimination for acquiring the disease, was greater in joint families. Although of no statistical significance this fear paralleled better education. Generally people from lower socioeconomic status had a fatalistic attitude and tended to ignore self-help measures.

Many worries about divorce due to leprosy were manif ested in subtle ways such as becoming upset or angry over trivial matters. This tendency affected more women from joint rather than nuclear families. Apart from constraints due to poverty and large family size, this study shows that leprosy creates an additional psychological burden on women.

The different ways in which leprosy affects the psychology of the individual have been studied by other workers (Table 5) and showed much higher figure in women than men, accounting for their aggressive behaviour. The difference between the psychosocial aspects of other studies and the present study was found to be statistically significant, probably because our study was confined to women.

It has been noted ${ }^{25}$ that a majority of leprosy patients were physically, socially and psychologically maladjusted. Patients were found to be withdrawn and isolated. In our study $15 / 50$ of women preferred to stay alone.

The psychological impact of other chronic infections and deformities due to causes other than leprosy have also been studied. The victims of vitiligo experienced more psychological symptoms of free floating anxiety and depression than normal healthy individuals. ${ }^{26}$ Compared to tuberculosis, ${ }^{27}$ the fear of social ostracism was greater amongst leprosy patients because of visible stigmata. Cancer patients were also found to be depressed, using denial mechanism to ward off severe degrees of anxiety, tension and insecurity generated by the illness. ${ }^{28}$ In a study of orthopaedically handicapped children and their families, there was a preponderance of denial reactions as a psychological defence mechanism in facing reality. ${ }^{29}$ Recognizable psychological disturbances in children and their parents have been recorded after burns. ${ }^{30}$

\section{PROBLEMS FACED IN TAKING REGULAR TREATMENT}

Treatment of leprosy is prolonged and raises several problems for ensuring compliance. To alleviate this, we provided railway concession forms and some monetary aid. However, this proved insufficient to cope with financial limitation in the lower socioeconomic group.

Another important factor is the availability of a family member to take the patient to the clinic. In our study $16 / 50$ patients were accompanied by a family member. This is particularly desirable during pregnancy since we found that nearly half of the women in the reproductive age group became pregnant during the course of the disease. Although the majority continued with their treatment, few (3/19) discontinued from fear of adverse effects on the child, leading at times to medical termination of pregnancy (MTP). 
For a lay person leprosy is synonymous with disfigurement that sets the patients socially apart from others. Many (29/31) women in the present study with either patches or deformities felt embarrassed and feared attracting the attention of others to their physical imperfections. This proportion is a little higher than that conducted in a similar city in which $27 \%(25 / 91)$ of the sample group consisted of women. ${ }^{31}$

Almost half (14/31) the patients faced problems at work due to anaesthesia and deformities, worsened by complications like ulceration, paralysis, the wasting of muscles and the mutilation of body parts. Patients were suspicious whether the disease could be cured and expressed apprehension of progression of deformities.

\section{DISABILITY AND ITS EFFECT ON WORKING EFFICIENCY}

Two-thirds of the patients with deformity had mild disability. The severity of disability, pain and repeated ulceration directly affected efficiency, similar to a previous report. $^{31}$

\section{Solutions}

It can be seen from the study that social and psychological problems faced by women suffering from leprosy were mainly due to the associated social stigmata. The attitude of the husband and family even after cure influences the psychological milieu of the patient immediately from the making of the diagnosis of the disease. Hence, it is essential to educate not only the patients, but also families and communities. Emphasis should be given to bringing about changes in attitude and practices. With the family and society accepting the patients, they are more likely to come forward for early and regular treatment, thereby minimizing or preventing deformities and disabilities.

Social and psychological support should be given importance. Counselling has been recognized as desirable but not been implemented adequately. It is essential in maintaining motivation to comply with treatment, and combating social and psychological problems of daily living since anaesthetic areas, hypopigmented patches and deformity that persist after treatment may raise social barriers.

Nearly half of the patients attending the ULCs have to travel a long way for treatment. In India, women face difficulties in continuing the treatment if it is not provided nearby. In any control programme facilities for treatment should be at accessible distances for women and children. In addition, financial assistance should be provided for reconstructive surgery and occupational therapy.

\section{Conclusions}

Women with leprosy face definite social and psychological problems irrespective of their socioeconomic status.

Stigmata may result in strained relationships between the women, their husbands and family members. 
Discriminative attitudes and fear of spreading infection are more common in joint families than nuclear ones.

Greater notice is taken of stigmata among the educated class.

The presence of deformities or visible patches have a bad psychological impact upon the patients.

\section{References}

1 World Health Organisation. Towards elimination of leprosy. Leprosy Control Programme. WHO/CTD/ LEP, Geneva, 1991.

2 Sansarricq H. Leprosy in the world today. Lepr Rev (Suppl. 1), 1981; 52: 15-31.

${ }^{3}$ Noordeen SK. A look at world leprosy. Lepr Rev, 1991; 62: 72-86.

${ }^{4}$ Kumar A, Anbalagan M. Socio-economic experiences of leprosy patients. Lepr India, 1983; 55: 314-21.

5 Eldarons AH, Kamel Z, Ahmad F. Divorce among Saudi Female leprotic patients: an experience at Ibn Sina Hospital-Letter to the Editor. Lepr Rev, 1993; 64: 166-9.

${ }^{6}$ Mutatkar RK. Social Aspects of Leprosy. In: A Window on Leprosy (Gandhi Memorial Leprosy Foundation), Edited by Chatter jee BR, 1978; 1-6.

7 Cakiner T, Yuksel A, Soydan M, Saylan T, Bahceci E. Women and leprosy in Turkey. Ind J Lepr, 1993; 65: $59-67$.

${ }^{8}$ Kant VP. Socio-economic problems of leprosy patients and their relatives in Gujarat State. Ind J Lepr, 1984; 56: $889-99$.

9 Naik SS, Hambarde PS, Desai AN. Problems and needs of women leprosy patients in Bombay and Goa-a preliminary report. Ind J Lepr, 1991; 63(2): 213-17.

10 Kushwah SS, Govila AK, Upadhyay S, Kushwah J. A study of social stigma among leprosy patients attending a leprosy clinic in Gwalior. Lepr India, 1981(a); 53: 221-25.

11 Reddy BN, Bansal RD. An epidemiological study of leprosy disability in leprosy endemic rural population of Pondicherry (S. India). Ind J Lepr, 1984; 56: 191-9.

12 Vasundra MK et al. A study of medico-social problems of the inmates of a leprosy colony in Mysore. Lepr in India, 1984; 55: 553-9.

${ }^{13}$ P Kaur, Gurmohan Singh. Deformities in leprosy patients attending urban leprosy clinic at Varanasi. Ind J Lepr, 1985; 57: 178-92.

${ }_{15}^{14}$ Fine PEM. Leprosy: the epidemiology of a slow bacterium. Epidemiol Rev, 1982; 4: 161-88.

15 Girdhar M, Arora SK, Mohan L, Mukhija RD. Pattern of leprosy disabilities in Gorakhpur (UP). Ind J Lepr, 1989; 61: 503-13.

${ }^{16}$ Ramanathan U, Srivastav I, Ramu G. Psychiatric morbidity in patients with leprosy. XII International Leprosy Congress Proceedings, New Delhi, February 20-25 (1984); 810-11.

17 Chatter jee RN, Nandi DN, Banerjee G, Sen B, Mukherjee A, Banerjee G. The social and psychological correlates of leprosy. Ind J Psychiatry, 1989; 31(4): 315-18.

${ }^{18}$ Ma H, Ye G-Y, Shu H-W, Jiang C, Zhou D-S. Studies on social medicine and leprosy in east China. Proc CAMS and PUMC, 1989; 4: 61-4.

19 Kumar JHR, Verghese A. Psychiatric disturbances among leprosy patients—an epidemiological study. Int J Lepr, 1980; 48: 431-4.

20 Verghese A, Beig A, Senseman LA, Sunder Rao PSS, Benjamin V. A social and psychiatric study of a representative group of families in Vellore town. Ind J Med Res, 1973; 61: 608-20.

21 World Health Organisation. Fourth Expert Committee on leprosy. Classification of deformities. Geneva, 1970.

${ }^{22}$ Caradoc-Davies TH. T ADPOLE III. Elsevier-BIOSOFT, Netherlands, 1987.

${ }^{23}$ World Health Organisation Report. Epidemiology of leprosy in relation to control. Tech Rep Ser, 1985; 716: 24.

${ }^{24}$ Ramu G, Dwivedi MP, Iyer CGS. Social reaction to leprosy in a rural population in Chingleput District (Tamil Nadu). Lepr in India, 1975; 47(3): 156-69.

${ }^{25}$ Sabesan S, Ramanaiah TBBSV, Bidarakoppa GS, Jeyasingh P, Mohan A. Adjustmental problems of leprosy patients. Ind J Lepr, 1987; 59: 84-91.

${ }^{26}$ Uma Devi. A comparative study of psycho-social dynamics of leprosy patients among rural and urban communities of Vijayawada, Krishna District (A.P.). Project Report, ICMR, 1992.

27 Gera SH. Psycho-social factors in tuberculosis. Gitanjali Publishing House, New Delhi, 1992.

${ }^{28}$ Patel MJ, Sinha BK, Gawadia ML. Psychological manifestation in Cancer patients. Ind J Clini Psychol, 1980; 7: $147-50$. 
${ }^{29}$ Emotional reactions of orthopedically handicapped children in feelings and their medical significance. Ross Laboratories, Valley Stream, NY, Vol. VII, Jan. 1965; 1.

30 Vigilians A, Hart L, Singer F. Psychiatric sequelae of old burns in children and their parents. Amer J Orthopsych, 1964; 34: 753-61.

31 Janet E. Price. A study of leprosy patients with deformities and the implications for the treatment of all leprosy patients. Lepr Rev, 1983; 54: 129-37.

\section{Appendix}

SUBJECT-SOCIAL PROBLEMS OF WOMEN LEPROSY PATIENTS

Interview Schedule

Case No. Date

I. Identification data

Diagnosis

A. Individual information

1 Name

2 Age $\quad$ Sex

3 Address

4 Educational status

5 Marital status-Single/Married/Separated/Divorced/Widowed

6 No. of children (if any)

7 Occupation__ Income (if any)

8 Status in the household

9 Caste

10 Religion

B. Household information

11 Household income (approx.)

12 Particulars of the household members

Name Sex/Age Relationship Education Occupation (if any)

II Information on disease status

13 Deformity status due to leprosy (if any)

14 Presenting complaints

15 History of other chronic diseases (if any)

III Interaction with household/society

A Interaction with household members

16 Are members of the family aware or not aware of the disease?

Aware / Not aware

17 Is there any discrimination within the family due to the disease?

Discrimination / No discrimination 
(i) Do they find fault only with you more frequently?

Yes / No

(ii) Are you abused (due to leprosy) while taking part in family matters? Yes / No

(iii) Do the family members avoid taking food with you?

Yes / No

(iv) Are you prevented from using common articles of daily use?

Yes / No

(v) Are you allowed to participate in the family functions?

Yes / No

(vi) Do the family members hesitate in mixing with you?

Yes / No

(vii) Are you allowed to sleep in the same place as your family members?

Yes / No

(viii) Is your bedding kept with the bedding of the family?

Yes / No

(ix) Do the family members refuse to wash your clothes?

Yes / No

(x) Do the family members refuse to wash your utensils?

Yes / No

(xi) Do the family members ask you to cook separately?

Yes / No

(xii) Were you distanced by the family members/relatives after contracting the disease?

Yes / No

(xiii) When you are sick, do the family members take care of you or are you left alone?

Take care / Left alone

(xiv) Are you taking part in important decision-making matters in the family?

Yes $\quad /$ No

Relationship with the spouse

18 Does your spouse stay with you?

Yes / No

19 If yes, how are your conjugal relationships with him at present?

20 If divorced, give reasons?

21 Were you allowed or not allowed to breastfeed your children to be close to them?

Allowed / Not allowed

Interaction with community people

22 Are your friends/villagers/neighbours aware or not of your disease?

Friends -Aware / Not aware

Villagers - Aware / Not aware

Neighbours - Aware / Not aware 
23 Do the community people prevent you from using common places? like,
Yes Temple
No
Well
Yes / No
Tank
Yea / No

24 Do the community people allow you to sit with them when partaking feasts?

Yes / No

Few-

Mostly-

All-

25 Do the community people constantly abuse you or not, and do they or do they not ask about your disease?

Yes / No

Interaction with the colleagues/employers at work place

26 Are you continuing with the same job that you were doing before contracting the disease?

Yes / No

27 Are your colleagues/employers at the work place aware or not aware of your disease?

$\begin{array}{lll}\text { Colleagues - } & \text { Aware } & \text { Not aware } \\ \text { Employers - } & \text { Aware } & \text { / Not aware }\end{array}$

28 Do you or do you not face problems in getting work in the village/locality?

Yes / No

29 Does your employer pay you less or the same as other workers?

Yes $/$ No

30 Do you get common facilities from your employer like the others?

Yes / No

31 Do your colleagues take or refuse to take food with you?

Yes / No

32 Do the colleagues maintain a distance in the work place?

Yes / No

33 Do your colleagues try to influence your employer to dismiss you from your job? Yes / No

34 If yes, state reasons.

35 Are you or are you not allowed to take paid or unpaid leave to attend the clinic? Allowed / Not allowed

\section{Psychological problems}

36 Do you think you are cured now (for those released from treatment)/getting cured (for those taking treatment)?

$$
\text { Yes } / \text { No }
$$

37 If no, why. 
38 Are you or are you not worried about the infectivity of the disease?

Worried / Not worried

39 Have you or have you not distanced yourself from the family after contracting the disease?

Yes / No

40 If yes, state reasons.

41 Are you or are you not worried about divorce?

Worried / Not worried

42 Do you or do you not become angry over trivial matters?

Yes / No

43 Do you or do you not become upset easily?

Yes / No

44 Do you or do you not prefer to stay alone?

Yes / No

\section{Level of communication}

45 Do you hesitate to tell your problems to your family members/doctor/social worker?

Yes / No

46 Are you able to come to the clinic on your own or do you depend on others to bring you to the clinic

Alone / Accompanied

V Problems of treatment compliance

47 Are you attending clinic regularly?

Yes / No

48 If no, state reasons.

49 Are you taking your medicine regularly?

Yes / No

50 Do you take care of your hands, feet, eyes, as advised?

Yes / No

51 Are you able to perform your desired duties after contracting the disease? like

- Household work

- Job, if employed

Yes / No

52 Is there any chronic ulcer?

Yes / No

53 If yes, since when and how did you get it?

VI Economic problems

54 Do you get problems in attending clinic regularly because of the travel expenses? Yes / No 
55 If dependent, do the family object to giving you the money for travel?

Yes / No

56 If employed, have you been able to perform your required duties after contracting the disease?

Yes / No

57 Are you able to earn same/more/less after contracting the disease?

58 Are you losing your work days/daily wages for attending clinic/due to disease complications?

Yes / No

Complications due to deformities

59 Do you or do you not feel embarrassed by physical imperfection?

Embarrassed / Not embarrassed

60 Do you or do you not fear that people would ask about the deformity?

Fear / Not fear

61 Do you or do you not fear that people would recognize the disease by seeing the def ormity?

Fear / Not fear

62 Do you find problems while working because of deformity? Explain.

63 Are you concerned about the future? Explain.

VII Physiological problems

64 Have you been pregnant since contracting the disease?

Yes / No

65 Did you continue with your treatment during pregnancy?

Yes / No

66 Did you breastfeed your child?

Yes / No

67 If no, state reasons? 